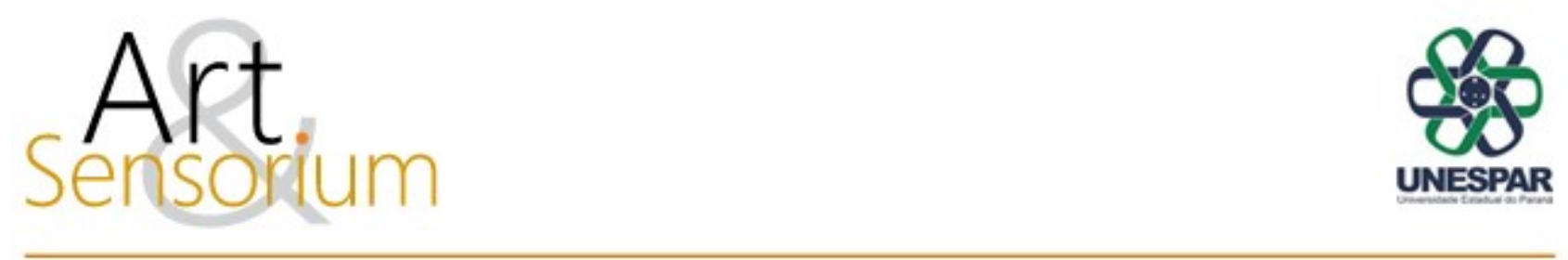

\title{
O ENTRETENIMENTO ONLINE - A SOCIEDADE ESPETACULAR DAS LIVES NOS TEMPOS DE PANDEMIA
}

\author{
DOI: https://doi.org/10.33871/23580437.2020.7.2.193-206
}

\author{
Mayra Terra Maluf de Araujo ${ }^{1}$ \\ Alberto Cipiniuk ${ }^{2}$
}

\begin{abstract}
Resumo: A suspensão temporária de uma parte das atividades coletivas, foi uma das consequências impostas na pandemia de Covid-19. Alguns setores sociais tiveram suas atividades presenciais paralisadas por completo em parte do primeiro semestre de 2020 no Brasil, como por exemplo o de entretenimento e artes. Como uma possibilidade de reverter a estagnação total do campo, alguns eventos artísticos foram transformados e ocuparam as plataformas online. Esta pesquisa irá investigar o panorama das lives de música no país durante este período e como o mercado de shows se ajustou a esta nova realidade momentânea. Levaremos em conta não apenas os aspectos próprios da indústria cultural, mas também as questões sociais que fazem das apresentações ao vivo um lazer compartilhado e enraizado na nossa cultura e sociedade. O espaço de circulação de conteúdo da internet pode parecer democrático a uma primeira análise, porém com o boom das lives ficou evidente como esta concepção é equivocada. Os sistemas de patrocínio, divulgação e circulação destes eventos online, reproduziram de forma muito similar o que ocorre nas apresentações ao vivo, ou seja, o monopólio da indústria cultural de massa.
\end{abstract}

As lives brasileiras foram campeãs mundiais de audiência, e atraíram grandes marcas patrocinadoras que logo as identificaram como um atraente espaço para ações de marketing. Porém para os artistas independentes o cenário foi outro, uma vez que sem o suporte financeiro, a estrutura de produção e o alcance das apresentações tiveram pouca expressividade. Deste modo, analisaremos o fenômeno das lives no Brasil e como a indústria do entretenimento se apropriou deste sistema, enquanto para os artistas autônomos a experiência foi extremamente distinta. E evidentemente, traçando os paralelos necessários com a recepção do público, a importância social do divertimento partilhado e sua transformação a partir de uma impossibilidade provisória.

Palavras-chave: Pandemia; Entretenimento; lives; Indústria Cultural

\footnotetext{
${ }^{1}$ Universidade Federal do Rio de Janeiro - UFRJ. Bacharel (2014), Mestre (2018) em Design pela PUC-Rio e cursando doutorado em Artes Visuais (previsão de término em 2022) pelo PPGAV - UFRJ. https://orcid.org/0000-0002-8528-1758. http://lattes.cnpq.br/4730714328974906.mayraterramaluf@gmail.com

2 Puc-Rio. Possui Licenciatura com Habilitação Plena em História da Arte pela Universidade do Estado do Rio de Janeiro (1978), mestrado em Filosofia Estética pela Universidade Federal do Rio de Janeiro (1985) e doutorado em Filosofia e Letras - Université Libre de Bruxelles (1990). Professor Associado e aposentado do Departamento de Teoria e História da Arte do Instituto de Artes da Universidade do Estado do Rio de Janeiro. Atualmente é Professor Associado da Pontifícia Universidade Católica do Rio de Janeiro. Tem experiência na área de Desenho Industrial, com ênfase em Desenho de Produto e Comunicação Visual, atuando principalmente nos seguintes temas: campo do design, design, história social da arte, comunicação visual e representação social da imagem. Líder de grupo de pesquisa registrado no Diretório do CNPq. https://orcid.org/0000-0002-4640-0646. http://lattes.cnpq.br/3763621130181471. acipiniuk@gmail.com
}

R. Inter. Interdisc. Art\&Sensorium, Curitiba, v.7, n.2, p. 193 - 206 Jul.- Dez. 2020 


\title{
THE ONLINE ENTERTAINMENT - THE SPECTACULAR SOCIETY OF LIVES IN TIMES OF PANDEMIC
}

\begin{abstract}
The temporary suspension of some collective activities was one of the consequences imposed by the Covid-19 pandemic. Some social sectors in Brazil had their in-person activities completely paralyzed in part of the first half of 2020, such as entertainment and the arts. As an option to reverse the total stagnation of the field, some artistic events were transformed and took place on online platforms. This study will investigate the universe of music "lives" in the country during this period and how the live music sector adjusted to this new momentary reality. We will take into account not only the specific aspects of the cultural industry, but also the social issues that make live presentations a shared leisure activity and something rooted in our culture and society. The space for the circulation of Internet content may seem democratic at first glance, but with the boom in "lives" it became evident how this concept is wrong. The systems of sponsorship, dissemination, and circulation of these online events were reproduced in a very similar way to what occurs at live inperson shows, or the monopoly of the mass culture industry. Brazilian "lives" were the most streamed online concerts in the world during the first half of 2020, and attracted major sponsoring brands that soon identified "lives" as an attractive space for marketing actions. For independent artists, however, the reality was different, since without financial support, the production structure and the scope of the presentations had little expressiveness. In this way, we will analyze the phenomenon of "lives" in Brazil and how the entertainment industry appropriated this system, while for independent artists the experience was extremely different. And clearly, drawing the necessary parallels with the public reception, the social importance of shared entertainment, and its transformation to a temporary impossibility.
\end{abstract}

Keyword: Pandemic; Entertainment; Lives; Cultural Industry

\section{ENTRETENIMIENTO ONLINE: LA ESPECTACULAR SOCIEDAD DE LAS LIVES EN TIEMPOS DE PANDEMIA}

La suspensión temporal de parte de las actividades colectivas fue una de las consecuencias impuestas por la pandemia de Covid-19. Algunos sectores sociales tuvieron sus actividades presenciales completamente paralizadas en parte del primer semestre de 2020 en Brasil, como el entretenimiento y las artes. Como posibilidad de revertir el estancamiento total del campo, algunos eventos artísticos se transformaron y ocuparon las plataformas online. Esta investigación indagará en el panorama de las lives musicales en el país durante este período y cómo el mercado de conciertos se ajustó a esta nueva realidad momentánea. Tendremos en cuenta no sólo los aspectos específicos de la industria cultural, sino también las cuestiones sociales que hacen de las presentaciones en vivo un ocio compartido y arraigado en nuestra cultura y sociedad. El espacio para la circulación de contenidos de internet puede parecer democrático en un principio, pero con el boom de las lives se hizo evidente que esta concepción es errónea. Los sistemas de patrocinio, difusión y circulación de estos eventos online, reproducen de forma muy similar lo que ocurre en las presentaciones en vivo, es decir, el monopolio de la industria cultural de masas.

Las lives brasileñas fueron campeonas mundiales de audiencia, y atrajeron importantes marcas patrocinadoras que pronto las identificaron como un espacio atractivo para acciones de marketing. Sin embargo, para los artistas independientes, el escenario era diferente, ya que sin apoyo financiero, la estructura de producción y el alcance de las presentaciones tenían poca expresión. De esta manera, analizaremos el fenómeno de las lives en Brasil y cómo la industria del entretenimiento se apropió de este sistema, mientras que para los artistas independientes la experiencia fue sumamente diferente. Y evidentemente, trazando los paralelos necesarios con la recepción del público, la importancia social del entretenimiento compartido y su transformación desde una imposibilidad provisional.

Palabra clave: Pandemia; Entretenimiento; Lives; Industria-cultural 


\section{Introdução}

A paralisação integral de praticamente todos os espaços coletivos de coesão social, pelo menos aqueles que solicitam o comparecimento físico das pessoas, em escala global como consequência da pandemia do Covid-19, alterou por completo grande parte do consumo de bens culturais em todo o mundo. Estas mudanças afetaram a maneira de como os produtos culturais circulavam em todos os gêneros artísticos, uma vez que uma grande parcela deles demanda da participação ativa e presencial do público. Mesmo dentro das categorias artísticas que, teoricamente, poderiam ser consumidas individual e remotamente (como é o caso da literatura através dos e-books), não podemos ignorar o fato de que todos os trabalhos artísticos são essencialmente coletivos, ou seja, a produção de qualquer atividade cultural e comercial, é feita para as pessoas e através delas, ainda que empreguemos suportes tecnológicos para que isto aconteça.

Que o distanciamento social imposto gerou mudanças drásticas nos espaços urbanos e nas suas dinâmicas sociais, é um fato inquestionável. Mas apesar disso, muitas atividades sofreram processos de transformação para que pudessem, em alguma instância, continuar ocorrendo. As grandes mídias alardeiam que as plataformas online serviram como principal suporte na tentativa de permanência de determinadas práticas sociais e cotidianas em meio a este momento singular. Os pares do Campo da Arte se posicionaram através de estratégias distintas e de acordo com seus setores e possibilidades. Vale frisar que não consideramos a atividade artística tal qual a visão hegemônica romântica que trata seu consumo como algo secundário, ressaltando como primordial as crenças ligadas ao dom inato e a necessidade quase vital da expressão individual do artista. Neste breve ensaio, conduziremos nossa abordagem sob a perspectiva social da arte, que considera os aspectos referentes à comercialização, os processos de legitimação, os sistemas de patrocínio e todas essas características inerentes ao capitalismo em relação à forma como este modo de produção opera na circulação dos produtos que produz. Esses dados serão tidos como essenciais para a análise. Posteriormente nos aprofundaremos nestas questões, porém por ora nos basta considerar que toda a abordagem teórica se dará a partir de considerações acerca do consumo cultural no Brasil, fitando com atenção a baliza temporal referente ao primeiro semestre de 2020, temporalidade que julgamos ter alterado inúmeras formas de representação artística.

Os pares do Campo da Arte o subdividem em categorias artísticas ou gêneros distintos, em que cada um deles existem demandas específicas, os seus espaços de circulação particulares. A maneira como os produtos culturais entram em circulação no meio social, assim como a sua condição de entretenimento nos ficam mais evidentes uma vez que os museus, os cinemas, os teatros, as casas de show, as livrarias e todos as manifestações destinadas ao público foram proibidas de operar. Entretanto ao tratar da produção da arte que é anterior a exibição, pode ocorrer o equívoco de considerarmos que determinadas práticas são individuais enquanto outras são coletivas. Ora, muitos de nós consideram que a prática profissional do pintor pode continuar acontecendo durante o período de isolamento, pois o senso comum, o habitus social, afirma que o pintor trabalha sozinho em sua mansarda. Porém com a produção de filmes, a complexa intermediação de trabalhos para sua realização já não pode acontecer, pois a produção de um filme requer um grande número de pessoas para a sua execução. Não podemos dizer que não exista uma verdade nesta afirmação, porém até onde podemos enxergar ela nos parece ser equivocada, uma vez que devemos considerar que todo o mercado de arte é essencial ao trabalho do pintor, pois a verdade da obra de arte, digamos assim, começa no momento do seu consumo. E com a sua paralisação a demanda do trabalho também sofrerá alterações nas condições primordiais. O pintor produz para exibição em galerias, feiras de arte e outros espaços de exibição. Nestes lugares é onde ocorre a venda, onde as obras circulam, quando o mercado desacelera e as exposições são suspensas, a consequência é direta. Ainda que consideremos o caso da pintura um caso muito particular dentro do Campo da Arte podemos afirmar que mesmo ocorre com os filmes. 
Nossa intenção em trazer essa breve comparação entre a pintura e o cinema, é para sustentar que todos os Mundos da Arte, tal qual definiu Becker, sofreram danos diretos com as novas condições requeridas pelo momento presente, independentemente do fato de que alguns gêneros artísticos são considerados hegemonicamente como mais individuais e outros mais coletivos. Vale apontarmos rapidamente as distinções para Mundos da Arte explorado por Becker e a diferenciação que ele indica para Campos da Arte determinado por Bourdieu. Segundo o autor, a existência dos mundos da arte, além de considerar a produção e o consumo das obras, também demonstra a abordagem sociológica da arte (BECKER, 2010, p.27), “A análise centra-se sobre uma atividade coletiva qualquer. Algo que as pessoas façam em conjunto. Quem quer que contribua de algum modo para essa atividade e para os seus resultados faz parte desse mundo" (BECKER, 2010, p.305). E, ainda segundo ele a noção de campo é "o campo, limitado como é por regras e práticas que mantém os intrusos de fora, impossibilita que se faça parte de qualquer atividade coletiva a não ser que se seja escolhido pelas pessoas que já fazem parte dele" (BECKER, 2010, p.305). Desse modo, consideramos nesta pesquisa os participantes dos mundos da arte, para além daqueles que geralmente são apontados como célebres, como por exemplo atores, cantores, diretores, pintores, etc. Nossas considerações levam em conta os atuantes das equipes de apoio, profissionais menos distintos socialmente, mas fundamentais para a produção artística.

Ao discutirmos os impactos diretos nas artes devido ao cerceamento da circulação das obras de arte durante a pandemia, estamos sustentando que não apenas a forma de produção se alterou, como também a distribuição e a recepção em relação ao seu público. Nosso recorte neste trabalho pretende trazer uma breve análise acerca da adaptação dos espetáculos musicais durante este período. Ou seja, o deslocamento do ambiente físico dos shows e concertos, para o espaço online das lives. Um número muito grande de artistas no Brasil aderiu a esta plataforma ou suporte para a manutenção da circulação dos trabalhos artísticos, embora o acesso, a comercialização e a periodicidade, tenha variado muito. Tanto cantores com grande público e com vínculo reconhecido com os meios de circulação tradicionais, tal como as gravadoras, quanto artistas independentes e de pequeno alcance se apresentaram das suas casas (ou espaços privados), para um público que acompanhou das telas de seus celulares, computadores e televisões.

O grande boom das lives durante esse período, alterou a forma como os artistas e o público se relacionaram entre si e com os modos operativos de circulação dos produtos da indústria cultural do espetáculo. Shows que antes presencialmente eram locais, passam a atingir uma possibilidade de acesso em escala global. As equipes de apoio foram extremamente reduzidas e assim a geração de emprego desse setor tão amplo, foi diretamente afetada. Também já não existe o lucro da bilheteria, do bar, dos motoristas de táxi e aplicativos das regiões das casas de show, enfim, não se pode considerar que existe uma economia, uma maneira de como se distribuem ou se organizam as diferentes variáveis de uma dada totalidade. Para o público, o entretenimento se individualizou. Onde antes o espetáculo fazia parte de um lazer compartilhado, agora é desfrutado em casa, com qualquer roupa, como tradicionalmente se assistem às novelas e outros produtos da cultura de massa. Por outro lado, seria interessante lembrar que os shows ao vivo apresentados pela internet, sempre possibilitam um maior acesso, principalmente para pessoas que moram em pequenas cidades de interior (nas quais muitas vezes os artistas mais renomados não se apresentam), ou que não possuem renda para desfrutar deste tipo de lazer como pagantes. Entretanto também é importante observar que a estrutura das lives e dos shows presenciais são absolutamente distintos. E por mais que a plataforma online tenha surgido no intuito de suprir essa lacuna deixada pela impossibilidade de reuniões presenciais, a estrutura comercial e de lazer foram totalmente transformadas.

Neste trabalho, debateremos de forma panorâmica acerca das lives. Analisaremos a partir de um embasamento teórico, questões a respeito de algumas diferenças comportamentais e mercadológicas nesta adaptação de um entretenimento originalmente voltado para um lazer partilhado. Nos interessa investigar a relação do artista com a indústria cultural e com o público e sobre o público e a 
reformulação da noção de divertimento, uma vez que essa se individualiza nos espaços digitais, alterando por um todo o sentido simbólico do espetáculo. Desse modo, para a nossa escolha de autores, optamos por trabalhar com aqueles que têm pesquisas diretamente voltadas para o estudo do espetáculo e da indústria cultural de massa. Mesmo havendo algumas divergências teóricas entre eles, julgamos proveitoso evidenciar estas diferenças para o entendimento de um mesmo tema.

\section{O espetáculo online}

"O espetáculo não é um conjunto de imagens, mas uma relação social entre pessoas, mediada por imagens" (DEBORD,1997, p.14).

A Sociedade do Espetáculo, é o título da obra de Guy Debord e também poderíamos apontar este título como uma metáfora da forma como se estrutura a sociedade atualmente. Se em 1967 este livro já ilustrava o comportamento social espetacular, o gosto popular pelas grandes sensações, podemos dizer que ele ganha ainda mais notoriedade nos dias de hoje. O trecho destacado acima indica a absoluta influência da imagem espetacularizada ou sensacionalista nas relações sociais do cotidiano. O autor defendeu ao longo do seu livro que ocorria uma "coisificação" ou fetichização do indivíduo, que a partir de um consumo sistemático de mercadorias sob influência da publicidade, havia um esvaziamento da percepção acerca das questões sociais, da consciência de classe, do outro e de si próprio. Isto é, a forma de consumo do espetáculo estava diretamente vinculada as nossas escolhas individuais, que nos em geral nos parecem, equivocadamente, pessoais, porém não o são. A manutenção da certeza no livre arbítrio ou da capacidade da "livre" escolha dos artefatos que consumimos, é uma das crenças principais para a manutenção da sociedade consumo. O espetáculo é o equivalente abstrato das mercadorias (DEBORD, 1997, p.34).

No mundo virtual tudo pode ser considerado imagem, uma imagem manipulada para entreter, e na cultura de massa a imagem e o som são predominantes sobre a palavra. Uma live, que nada mais é que um show online ao vivo, pode se utilizar de recursos próprios do cinema, como por exemplo efeitos de câmera que nossos olhos não seriam capazes de efetuar. Giros em $360^{\circ}$ no ambiente, zoom em recortes específicos de aproximação ou afastamento, câmera lenta, desfoques pontuais e etc. A utilização desses artifícios simples e de natureza ilusionista, por si só já transformariam o modo de assistir um show ao vivo presencial e assim, a forma de recepção e interação deste público. Contudo, não podemos esquecer que arte é artifício ou fantasia e desde a Revolução Industrial os pares do campo defendem a ilusão frente às agruras da realidade. Assim, do mesmo modo que a relação do músico com o espectador se alterou com esta mudança de formato, podemos dizer que ainda estamos dentro da mesma mediação que outrora chamávamos - e com propriedade - de arte.

Walter Benjamin em seu texto A Obra de Arte na Era da sua Reprodutibilidade Técnica, debateu sobre o intérprete cinematográfico, definição que neste texto apresentaremos como similar a atuação dos músicos em lives. O autor destacava que "com a representação do homem pelo aparelho, a autoalienação humana encontrou uma aplicação criadora" (BENJAMIN, 1987, p.180), e que existia uma estranheza ou estranhamento do intérprete diante do aparelho que produzia a sua obra. Isso que Debord chamava de imagem espetacular, será, a partir de agora transportável e exibida para as massas. $\mathrm{O}$ intérprete quando está performando para as câmeras, na verdade já está se comunicando indiretamente com as massas, apesar dela não estar visível (BENJAMIN, 1987, p.180). Este distanciamento em relação ao público, também acontece nas lives, e o show apesar de ser transmitido em tempo real acaba por se aproximar de características próprias do cinema. Desse modo, podemos considerar que ocorre o que Benjamin chamaria de uma atrofia da aura, isto é, a perda da 
autenticidade, que é composta por elementos espaciais e temporais, o aqui e o agora, que ele definia como elementos fundamentais para a construção da obra de arte.

Antes de avançarmos seria preciso mencionar que não concordamos com a noção de "aura" no objeto artístico, conforme Benjamim postulou. A nosso juízo é estranha a definição deste grande pensador, pois trata-se de uma noção passadista, romântica ou idealista e não combina com o resto de sua produção teórica fundada no materialismo histórico e em noções como alienação e estranhamento. A compressão social do fenômeno artístico define a arte como uma atividade laboral tal como todas as outras e que a noção de criatividade não se deve a uma condição mágica ou misteriosa, mas resultado de práticas e relações sociais, enfim, que a arte não pode ser explicada por algum conceito prévio e de origem obscura.

Para prosseguirmos, é necessário que façamos uma breve síntese acerca do que estamos denominando de espetáculo contemporaneamente. Lipovetsky, por exemplo, abordará o tema defendendo que toda forma de espetáculo está ligada ao imperativo comercial, assim o capitalismo artista $^{3}$ gerou um império transestético no qual se mescla design e star-system, criação e entertainment, cultura e show business, arte e comunicação, vanguarda e moda. $\mathrm{O}$ autor ainda sustenta que o espetáculo na atualidade, ou como ele define, o hiperespetáculo, consagra a cultura democrática e mercantil do divertimento e que o capitalismo criativo atua com o cruzamento e a sobreposição do domínio e dos gêneros (LIPOVETSLY, 2014, p.28). Sabemos que a indústria do divertimento está diretamente ligada à indústria cultural de massa. E, muito antes do boom das lives, a música gravada já havia revolucionado a forma de se consumir música e democratizado o acesso. Porém a perda da possibilidade de assistir a um show presencialmente, causa outra reviravolta (possivelmente temporária) nesta indústria.

Os espaços de circulação e consumo da música se modificam constantemente e em grande velocidade. A música gravada, por exemplo, é cada vez mais difundida. Se no passado colecionávamos vinis, fitas cassetes e cds, que muitas vezes eram raros e de difícil acesso, hoje através da internet temos um alcance gigantesco de milhares e milhares de álbuns de todo mundo com facilidade grande e muitas vezes gratuitamente. ${ }^{4}$ Vale ressaltar que as transformações nas formas de se escutar música gravada ao longo da história, o modo de circulação deste gênero artístico, acarretaram em uma modificação na função social da música. A tecnologia de difusão em grande escala desta indústria da música gravada se inaugura no início do século XX, momento em que o mercado passa a ser dominado por 5 grandes gravadoras ${ }^{5}$, divididas entre EUA e Europa. Para termos uma noção deste alcance, em 1914 elas juntas venderam 50 milhões de cilindros ou discos no mundo inteiro (LIPOVETSKY, 2014, p.210). Por muitas décadas a apreciação da música gravada ainda era uma prática coletiva, familiar, da reunião em volta de vitrolas e rádios, de compartilhar a música em casa com outras pessoas. Apesar de já haver neste momento um processo de individualização no consumo de música se comparado a ida em concertos, isto ficará ainda mais latente a partir das décadas de 50 e 60. Com os rádios de pilha, ocorreu uma apropriação individual da música, o consumo musical passou a ser feito de forma

\footnotetext{
${ }^{3}$ Lipovetsky irá localizar o capitalismo artista dentro do que ele define como quarta era da estetização do mundo, a era transestética (era atual). Para o autor, neste momento os sistemas de produção e distribuição são governados por operações de natureza estética. E este novo estado da economia mercantil liberal de capitalismo, criativo e transestético, se intitula como capitalismo artista (LIPOVETSKY, 2014, p.40).

${ }^{4}$ Considerando gratuito aqui para aqueles que possuem os meios para acessar internet, o que sabemos que está longe de ser em escala global. Desse modo, a democratização completa desse recurso ainda é uma realidade distante.Estudo da ONU revela que mundo tem abismo digital de gênero. ONU News. 2019. Disponível em:

https://news.un.org/pt/story/2019/11/1693711. Acesso em 25/08/2020

5 São elas: Edison, Columbia, Victor (americanas), Pathé (francesa), Gramophone Berliner (grupo anglo-alemão) (LIPOVETSKY, 2014, p.210).
} 
particular - gravada - e a música, aparentemente, passou a criar um vínculo direto com a cultura do público jovem. Estas diferenciações na forma de se escutar a música gravada, mudou também a sua percepção de que passa a ser mais dispersa, o que Walter Benjamin vai chamar de "recepção na distração" (LIPOVETSKY, 2014, p.212). Essas transformações no consumo musical, aproxima a música ainda mais do consumo comum e o do entretenimento alienado.

Porém até o presente momento, a possibilidade de assistir a um show era concreta e quando possível exercida de forma complementar a escuta individual, por certo, o show se perpetua como lugar de encontro, de euforia e se podemos dizer de devoção. Parafraseando Guy Debord, "o espetáculo é a reconstrução material da ilusão religiosa" (DEBORD: 1997, p.19). O lazer compartilhado está para além da música tocada, independentemente se o espaço de exibição é mais formal, como uma ópera em um teatro, ou mais irreverente, como em uma roda de samba ou show de rock. Assistir a um show está ligado a diversão, a entretenimento, ao fato de praticamente sermos "obrigados" a nos arrumar para sair, a escolhermos uma roupa especial, arrumar os cabelos, nos banhar e perfumar, para encontrar e conhecer outras pessoas. É mais que um espaço de contemplação ou um momento de fruição estética. Trata-se de um momento de encontro social. O ato de cantar e dançar em conjunto, em um corpo a corpo com desconhecidos, é parte disso que faz do show um divertimento coletivo. A partilha do momento do espetáculo tem início com os pequenos grupos que se formam para irem juntos: casais, turmas de amigos, familiares, em nossa sociedade é mais comum irmos acompanhados que sozinhos a estes eventos. Ademais, na história da humanidade, a música é um dos fatores chave para a formação de grupos sociais, ela aproxima pessoas com gostos similares. O show ao vivo é o momento de encontro de pessoas que apreciam uma mesma coisa, com os mesmos valores sociais, fazem parte de um mesmo clube e vão ao espetáculo não apenas apreciar o ídolo, mas também ver e serem vistos por aqueles que se assemelham neste ponto em comum, que compartilham da mesma crença ou adoração. O consumo de massa na indústria do divertimento, não requer nenhuma cultura especializada. As pessoas em um mesmo espaço de shows, aparentemente podem não ter nada em comum além do apreço pelo artista e a vontade de estar naquele ambiente rodeado de outras pessoas e com elas realizar trocas sociais. A reunião de pessoas para adoração de alguém e o canto uníssono, já não está mais necessariamente ligada a religiosidade ou ritual. Inteligentemente o capitalismo a transformou em uma forma de produto ou mercadoria, contudo, disfarçada de uma glorificação do lazer pessoal. Esta troca social, uma verdadeira economia de trocas simbólicas, é parte da nossa sociedade e fundamental para o homem moderno. Os espaços de reunião de pessoas, de circulação cultural, de entretenimento conjugado, são fundamentais para a sociedade e para os indivíduos. Como seres sociais que somos, estes contatos e trocas fazem parte das nossas vidas e da estrutura da nossa sociedade.

A atual conjuntura está para além desta separação, as fronteiras entre as diversas práticas culturais se encolheram dando lugar a uma nova forma de presença, que não é física. O modo como a indústria fonográfica está operando hoje é devido às condições tecnológicas atuais, em outros tempos o cenário seria outro. A internet enquanto espaço de circulação ou difusão de conteúdos, mais especificamente a partir das lives de música, pode ser analisada através de duas vias distintas. Quando tratamos de artistas de pouco alcance, sem intermediários e produtores, com carreiras administradas pelos próprios artistas, notamos que a estrutura das apresentações é reduzida e obedecem a interesses próprios. Isto é, a ausência de um intermediário especializado altera a circulação do trabalho. Estes artistas independentes e de pequeno alcance nas redes digitais não estão incluídos na economia da sociedade e fazem parte do exército reserva de desempregados, digamos assim, que servem para o controle dos preços dos produtos em circulação. Em muitos casos exercem outra prática laboral para complementar a renda. Tocar e cantar marginalmente é uma atividade pouco prestigiada financeiramente no nosso país. Um fato concreto que evidencia essa realidade foi a aprovação da Lei Aldir Blanc no final de junho, que prevê um auxílio emergencial de $\mathrm{R} \$ 600,00$ para trabalhadores do 
setor cultural afetados pela paralisação do campo durante a pandemia ${ }^{6}$, e que com isso não estão sendo capazes de gerar receita, por não fazerem parte do pequeno circuito de pessoas que pôde se manter profissionalmente ativas devido as programações virtuais remuneradas. Suas apresentações online, também administradas de forma autônoma, em geral são distribuídas através de perfis pessoais em redes sociais e com uma estrutura de produção muito reduzida. Uma câmera de celular, um computador plugado ao microfone e ao instrumento, às vezes outros músicos e uma pequena equipe de apoio (se assim podemos chamar, pois em certos casos, quem exerce essas funções são sujeitos comuns não ligados aos mundos da arte, como amigos e familiares). A circulação deste material também acaba ficando reduzida a círculo social que o artista está inserido. Sem as exigências de um público grande e um sistema de agenciamento por trás, essas apresentações podem ser administradas integralmente pelo próprio artista. Isto é, quando se está inserido plenamente no mercado fonográfico de massa, são impostas determinadas limitações ou exigências a fim de atender a certas demandas baseadas em maiores retornos financeiros.

Antes de entrarmos na análise do segundo panorama das lives, que são os artistas de grande alcance vinculados indústria cultural de massa gostaríamos de tecer pequenas considerações sobre outra conjuntura de artistas independentes. Durante o período pandêmico as festas tradicionais regionais também foram interditadas. O São João nordestino por exemplo, é conhecido por suas centenas de shows e eventos ao longo de todo mês de junho. Nas apresentações, além da participação de artistas de grande alcance nas festas maiores, as exibições também são um espaço de circulação de muitos pequenos grupos regionais e que em geral tem um público local. Evidentemente, o fluxo financeiro proporcionado pelo turismo e pelo entretenimento nessas datas, são fundamentais não apenas para as cidades como para todos aqueles que atuam efetivamente nos eventos. Desse modo, algumas prefeituras e governos de Estados, bem como organizações sociais privadas como o SESC, financiaram lives de São João destinadas a esses artistas regionais. Exemplos disso são o Forró Pé de $\mathrm{Sesc}^{7}$ que ocorreu em Arcoverde - PE, com patrocínio da Secretaria de Cultura e Comunicação da Prefeitura de Arcoverde, da Fecomércio PE e do SESC, ou o Forró Dendi Casa ${ }^{8}$, patrocinado pela Secretaria de Cultura de Alagoas e a TV Alagoas. Um ponto em comum entre ambas foi o fato delas estarem abertas a doação de dinheiro a fim de proporcionar um auxílio financeiro para os participantes e equipes de apoio das lives, bem como outros grupos sociais em situação de vulnerabilidade devido a pandemia.

O que vale ressaltar neste momento acerca da diferenciação das lives individuais em primeiro lugar é o espaço onde foram filmadas as apresentações, uma vez que nesses eventos-live apoiados pelos governos, as apresentações ocorreram em palcos instalados em espaços privados, e com uma estrutura maior para comportar todos os grupos. Assim, o sofá e violão da vida privada do artista, dão lugar a uma estrutura mais semelhante a de um show ao vivo, o que transforma a relação do público, que ao mesmo tempo que se aproxima mais de uma experiência habitual de evento, se afasta mais da vida privada do artista nas lives caseiras, aspecto que constantemente gera curiosidade nos apreciadores. Além disso, este modelo de sistema de patrocínio difere muito dos patrocinadores privados da indústria cultural de massa como veremos mais adiante. Por ora concluiremos as considerações sobre esta categoria de lives atentando para o fato de que os artistas que estão de fora do circuito da indústria fonográfica, por mais que ocorram projetos de fomento e distribuição online durante a pandemia,

\footnotetext{
${ }^{6}$ Lei Aldir Blanc de apoio a cultura é regulamentada pelo Governo Federal. Governo do Brasil. 2020. Disponível em:https://www.gov.br/pt-br/noticias/cultura-artes-historia-e-esportes/2020/08/lei-aldir-blanc-de-apoio-a-cultura-eregulamentada-pelo-governo-federal .Acesso em 18/09/2020

7 Forró Pé de Sesc. YouTube .2020. Disponpivel em: :https://www.youtube.com/watch?v=IjkNA75CPUM\&t=6s. Acesso em 11/09/2020

${ }^{8}$ Forró Dendi Casa. YouTube. 2020. Disponível em: https://www.youtube.com/watch?v=zJrus7 vFPw .Acesso em $11 / 09 / 2020$
} 
continuam excluídos dos grandes meios de comunicação, circulando em setores pequenos (apesar da possibilidade global de alcance proporcionado pela internet) e financeiramente vulneráveis e pouco valorizados. Mesmo antes da pandemia, grupos regionais sempre estiveram submetidos a uma hierarquia econômica e estética perante os artistas da indústria cultural de massa. José Jorge de Carvalho, no seu artigo 'Espetacularização' e 'canibalização' das culturas populares na América Latina, de 2010, apontava para essa característica das atividades culturais no Brasil. Ele usava como exemplo o cachê pago com verbas públicas pela prefeitura do Recife para um show de Natal em 2004, no qual a dupla de cantores Sandy \& Junior recebeu $\mathrm{R} \$ 400.000,00$ para se apresentar, enquanto cada grupo de Maracatu se apresentou no carnaval de Recife do ano seguinte por R \$ 800,00 (CARVALHO, 2010, p.43). Não é preciso aqui tecer considerações acerca da importância do Maracatu para a cultura pernambucana e a sua relevância na época de carnaval. Esse valor de verba mal cobre os custos básicos que demandam uma apresentação. Logo, mesmo com ações de verba pública, a desvalorização dos artistas independentes se perpetua.

A milionária indústria cultural de massa no Brasil, não abre brechas para que artistas independentes de fato se estabeleçam sem que haja uma interferência ou apoio de quem detém os meios de produção e difusão. Por vezes podemos crer que a internet proporciona um espaço democrático de circulação de conteúdos culturais, e de fato quem quiser se lançar de forma autônoma pode. Entretanto é muito difícil, senão impossível, que peixes pequenos consigam grande alcance e repercussão em um território dominado pelas grandes produtoras que detém o monopólio dos meios de comunicação. Se nos shows em espaços físicos isso era uma verdade, devido a fatores como aluguel de casas de show e contratação de grandes equipes de apoio, nas lives isso não se altera. Na plataforma do Youtube por exemplo, para que se possa fazer uma live, é necessário que o artista tenha no mínimo mil inscritos no seu canal, o que já delimita quem pode fazer uma apresentação. ${ }^{9}$ Vale frisar que o Brasil liderou o ranking mundial de audiência de lives no YouTube durante a pandemia. ${ }^{10} \mathrm{E}$ não é necessário dizer que todos os artistas neste ranking estão absolutamente vinculados a indústria cultural de massa. A empresa se beneficia financeiramente nas exibições de conteúdo de duas formas, a primeira é com a arrecadação das assinaturas dos serviços pagos e a outra através do percentual das receitas geradas com anúncios.

O princípio das lives na pandemia teve origem com artistas internacionais como Chris Martin, do Coldplay gravando do seu próprio celular em meados de março, ou Elton John da sua cozinha para uma transmissão beneficente para arrecadação de doações. ${ }^{11}$ No Brasil, as grandes produções vinculadas a marcas patrocinadoras, chamadas super-lives tiveram início com o sertanejo Gusttavo Lima em uma transmissão pelo Youtube no final de março patrocinada pela cervejaria Bohemia. Com

${ }^{9}$ Restrições na transmissão ao vivo. Google Support. 2020. Disponível em:

https://support.google.com/youtube/answer/2853834?hl=pt-BR. Acesso em 18/09/2020

${ }^{10}$ Marília Mendonça e Jorge e Mateus têm as lives mais assistidas do mundo na quarentena. Folha de S.Paulo.2020. Disponível em:

https://f5.folha.uol.com.br/musica/2020/05/marilia-mendonca-e-jorge-mateus-tem-as-lives-mais-assistidas-domundo.shtml Acesso em 11/09/2020

11 Como as lives se tornaram centrais para os artistas da música. Nexo Jornal. Disponível em: https://www.nexojornal.com.br/expresso/2020/04/09/Como-as-lives-se-tornaram-centrais-para-os-artistas-dam\%C3\%BAsica: Acesso em: 10/09/2020

Show comandado por Elton John arrecada 8 milhões para caridade. G1. 2020. Disponível em: https:/g1.globo.com/poparte/musica/noticia/2020/03/31/show-comandado-por-elton-john-de-casa-arrecada-us 8-milhoes-para-caridade.ghtml.

Acesso em: 10/09/2020 
audiência de 700 mil espectadores simultâneos, a live também se apresentou como beneficente, a fim de arrecadar fundos para doação de alimentos e equipamentos de segurança a famílias afetadas pelo Coronavírus. Esse número de audiência foi pequeno comparado ao que estava por vir, como a sertaneja Marília Mendonça com 3,3 milhões de visualizações simultâneas no início de abril, com patrocínio da Havaiana. Essas quantidades tão elevadas de público tornaram-se um atraente cenário para as ações de marketing. Outros artistas consagrados da MPB, que fizeram lives mais intimistas em casa, também receberam patrocínios e tiveram ações de marketing em suas apresentações, como por exemplo o Alceu Valença com a cerveja Colorado (AMBEV), Gilberto Gil com a cerveja Devassa (Brasil Kirin) e Zeca Pagodinho com a cerveja Brahma (AMBEV).

Não podemos ignorar o fato que o sistema de patrocínio sempre tomou conta dos espaços de difusão de música. Os shows e festivais de grande escala de modo geral dependem das grandes marcas como fomentadoras. Sabemos que a estrutura de um espetáculo possui custos elevadíssimos e dependem de uma cadeia enorme de profissionais, deixando praticamente inviável o financiamento de toda estrutura de forma autônoma pelo artista, que também precisa lucrar. Os hiperespetáculos dos nossos tempos, e particularmente no campo do show business são fundamentalmente a indústria do divertimento. Segundo Lipovetsky “a economia está cada vez mais na cultura, e esta na economia: à economização crescente da cultura corresponde a culturalização da mercadoria" (LIPOVETSKY, 2014, p.262) (me desculpe o Lipovetsky, mas aqui eu acho que foi a economia que tomou de assalto a cultura e não que a cultura "migrou" para a economia, correto?). Ainda segundo o autor, a relação com as coisas não é mais predominante, o que se busca hoje são "experiências variadas" e distrativas, na lógica do consumo de animação e renovação de memórias (LIPOVETSKY, 2014, p.313). A indústria cultural - o mudo de produção capitalista - passou a se encarregar da estetização deste divertimento e se colocou em todos os setores culturais, e desse modo ela mesma que dita as regras do consumo e do gosto através da oferta e da publicidade. Em poucas palavras o mercado criou as suas próprias demandas e também as controla, o que significa que aquilo que hegemonicamente compreendemos como "tendências" culturais - trends and forecasts - não são fenômenos que surgem de forma espontânea. Não estamos defendendo que o artista não tenha poder de decisão acerca da sua própria produção, porém é preciso admitir que ele também está a serviço desta indústria. Becker já apontava para a intervenção dos intermediários especializados nos sistemas de distribuição, que também podemos identificar como produtores, que por vezes obedecem a interesses diferentes dos interesses dos artistas com o qual trabalham, procurando racionalizar, disciplinar e monetizar em cima de uma atividade criativa, a fim de garantir uma estabilidade nos seus negócios (BECKER, 2010, p.100). Se, no passado a figura do mecenas nas artes era algo legítimo, porque hoje não o apontamos mais como cabível em detrimento a noção da genialidade individual artística? As diferenciações entre os sistemas de patrocínio dos shows convencionais e das lives são inúmeras, o hiperespetáculo deu lugar momentaneamente as super-lives, e cabe a nós agora debatermos acerca disto que estamos intitulando como mecenato online.

Os sistemas de mecenato em geral são atribuídos a artistas plásticos, literatos e músicos da corte do passado, porém, esta figura hegemônica do mecenas como um nobre que encomenda retratos, acrósticos e missas fúnebres é um tanto limitada. O mecenas pode ser o Estado, a Igreja, uma empresa privada, ele é um organismo que paga integralmente pelo trabalho de um artista durante um período determinado. Assim os mecenas mais poderosos financeira ou socialmente, acabam por controlar as possibilidades de exibição ou interpretação das obras que financiam, e a partir destes monopólios moldam os gostos dos outros (BECKER: 2010, p.104 - 105). No capitalismo os sistemas de mecenato constituem uma relação direta entre os interesses do investidor com a prática dos artistas. Nas artes de espetáculo, que é o nosso campo de debate, o mecenas ganha outro nome - produtor - e sua relação com o artista e o mercado também se altera, devido aos custos extremamente elevados das estruturas dos espetáculos contemporaneamente, sendo inviável para o mecenas os assumir sozinho (BECKER: 2010, p.107). Logo, vale ressaltar que o que atribuímos aos sistemas de patrocínio e agora ao trabalho do produtor são práticas distintas, apesar das terem influência direta no trabalho do artista que será 
apresentado ao público. Ambos enquanto intermediários, garantem a comercialização e difusão dos artistas e a possibilidade de apresentação a grandes públicos, que por sua vez têm seus gostos formados pelos mesmos, já que são os financiadores e intermediários que vinculam determinadas pessoas aos meios de comunicação de massa. Um espetáculo em toda sua complexidade (que vai desde a escolha do local, do repertório, do figurino, cenário, preço do ingresso, etc..), é uma tomada de decisões coletiva que integra o trabalho que o artista deseja mostrar e os interesses financeiros e as estratégias de marketing dos produtores e patrocinadores. Apesar de até os dias atuais a noção passadista do artista como gênio inato se perpetuar, não podemos cometer o equívoco de ignorar que ele está a serviço da indústria multimilionária do entretenimento. Desse modo o artista responde aos interesses financeiros dos intermediários ou mediadores da circulação, que operam como a embreagem de um automóvel, liberando ou calibrando as velocidades do motor, para que se mantenha no circuito que o integre na economia da sociedade e possibilite que ele viva exclusivamente da arte. Seria ingênuo pensar que a indústria cultural se volta mais para a qualidade artística do trabalho do que para a venda de ingressos e álbuns. Segundo Becker "às exigências das indústrias culturais engendram uma uniformização mais ou menos importantes dos produtos, que traduz menos uma escolha dos autores da obra do que as propriedades do sistema" (BECKER: 2010, p.125). A indústria cultural se vale da pasteurização artística para diminuir a margem de erro nas apostas em determinados artistas. Logo, é possível afirmar sem medo de sermos refutados, que o público é moldado de acordo com esses interesses de quem detém o monopólio dos meios de comunicação.

Quando tratamos das lives, toda a cadeia produtiva do show se altera e assim também se modificam os custos de produção e de arrecadação. O aluguel das casas de show, as gigantescas equipes de apoio, o funcionamento do bar, o lucro com bilheteria, tudo isso é absolutamente transformado. Se neste modelo online o lucro do produtor não está mais vinculado às atividades tradicionais de retorno monetário direto do lazer compartilhado (como a compra e venda de ingressos e de bebida por exemplo), agora o sistema de patrocínio toma a dianteira inconteste nas operações financeiras que envolvem um espetáculo, onde o retorno direto já não existe. O patrocinador arca com os custos em troca de ações de publicidade. Desse modo, quanto maior a audiência, mais interessante e lucrativo o negócio se torna para a marca patrocinadora. Vale apontar para o fato de que as lives não têm a limitação de público que os espaços físicos possuem. E apesar de os shows presenciais, principalmente os de grande escala, também apresentarem apoiadores e patrocinadores, a cadeia financeira se estendia para outros setores do consumo. $\mathrm{O}$ que desejamos evidenciar aqui é qual o tipo de relação direta entre o conteúdo de uma apresentação artística, quando há apenas um patrocinador responsável por todos os custos. Sustentamos que o uso do termo mecenato online nestas circunstâncias foi uma escolha nossa por percebermos que este modelo das lives patrocinadas têm maior aproximação com os monopólios próprios dos mecenas. Enquanto um show ao vivo envolve geralmente um grupo de patrocínios e apoios, as super-lives tem como característica a concentração dos custos em apenas um provedor. Sabemos que este tipo de incentivo comercial não é feito de forma gratuita e desse modo nos questionamos até que ponto essas grandes marcas delimitam como se dará a show. De quem fica a cargo o repertório, o figurino, o local de atuação? Além disso, consideramos estas performances nas próprias casas dos artistas, como uma jogada de marketing para a aproximação do público com a vida privada do ídolo, e assim um retorno maior em número de espectadores. Todo esse ambiente voltado a vida íntima, reforça os processos de individualização do sujeito moderno. $\mathrm{O}$ ambiente compartilhado do show, deixa de existir não apenas nas questões espaciais, mas também simbólicas. A ideia do coletivo se dissipa por completo quando o show é levado para dentro da sala da casa do artista, e também do espectador. Espaços de apresentação sempre foram zonas compartilhadas, o carácter pessoal que se dá nas lives caseiras transforma toda simbologia da exposição coletiva, que obviamente já havia se deteriorado com a perda dos espaços físicos. Este modelo de transmissão nos parece bastante próximo das propostas dos reality shows com pessoas famosas, no sentido de que há uma tentativa de mostrar o astro como uma pessoa comum em seu ambiente próprio. Uma forma elaborada de criar a ilusão de proximidade entre o público e o ídolo, o 
que acaba por reforçar a individualização do sujeito, uma vez que ambos estão sozinhos e se conectando através de equipamentos eletrônicos. Os shows ao vivo televisionados, gravados em DVD ou disponíveis em plataformas de streaming já não são nenhuma inovação, porém ver a Ivete Sangalo de pijama em casa com o filho participando e o marido cozinhando ao fundo ${ }^{12}$, é uma novidade para o público, que também satisfaz a curiosidade, que é revertida nos tão almejados views. Aquilo que era feito pelos tabloides sensacionalistas e paparazzis, a tentativa de tornar a vida privada dos artistas algo público, passa a ser gerenciado por um sistema de patrocínio via YouTube. Contudo, não se pode esquecer que subjacente ao que se exibe na fachada é um disfarce da uberização de uma antiga forma de trabalho, ou seja, a fragmentação para a precarização ou enfraquecimento da forma trabalho em relação ao capital.

Por este formato das super-lives patrocinadas e pessoais se apresentarem como sendo algo extremamente novo, a legislação que diz respeito às regras e limitações destas apresentações, foram sendo desenvolvidas de acordo com acontecimentos polêmicos das lives inaugurais. Um exemplo disso foi a entrada de representação da Conar - Conselho Nacional de Autorregulamentação Publicitária - contra o cantor Gusttavo Lima pelo consumo excessivo de bebida alcoólica na live (que por sua vez foi intitulada como Buteco Bohemia em Casa) e responsabilizando a patrocinadora AMBEV. As denúncias se deram pela falta de mecanismos de restrição das lives a menores de idade, uma vez que houve o consumo irresponsável de bebida alcoólica por parte do cantor. A publicidade de bebidas alcoólicas é regulamentada pela Lei 9.294/1996 ${ }^{3}$ e pelo Código de Ética Publicitário do CONAR, e dentre as restrições referentes a patrocínio de marcas de bebidas alcoólicas, fica estabelecido que em eventos em plataformas diferentes da programação de televisão e rádio, a publicidade pode ser feita em qualquer horário (em televisão e rádio é permitido somente depois das 21h), desde que as marcas sejam identificadas apenas pelo sloogan, sem haver recomendação do consumo do produto. Depois deste episódio as regras das lives começaram a se alterar, havendo uma cobrança maior dos organizadores pelo cumprimento dos princípios de responsabilidade social e assim proibindo o consumo ao vivo, porém mantendo a propaganda e o patrocínio. ${ }^{13}$

As lives enquanto espaços de circulação de conteúdo cultural, ainda estão criando as suas próprias leis de comportamento e decoro. O acesso irrestrito de qualquer pessoa em qualquer idade, impõe as lives regulamentos distintos dos shows presenciais em espaços privados, que geralmente possuem uma faixa etária mínima de 18 anos. As regras das apresentações online se parecem mais com as da televisão e do rádio. E nos parece curioso pensar que as grandes patrocinadoras desses shows são as marcas de bebidas alcóolicas, uma-vez que estas não podem ser consumidas ao vivo pelos participantes. Nos eventos presenciais patrocinados por empresas de bebidas alcoólicas (como o Rock in Rio é patrocinado pela Heineken, e assim a marca detém o monopólio da venda de cerveja de todo o festival), o produto é comercializado no evento e geralmente sem abrir lugar para marcas concorrentes. Nas lives o mecanismo de lucro se dá apenas no âmbito da publicidade imagética, assim como na televisão. Os antigos sistemas de mecenato também não tinham como finalidade o lucro através de um mercado de compra e venda necessariamente. $\mathrm{Na}$ verdade, a distinção social e as relações de poder embutidas nesse patrocínio eram mais evidentes que o retorno financeiro direto.

\footnotetext{
12 Ivete faz live em casa de pijama. GSHOW.2020. Disponível em: https://gshow.globo.com/Famosos/fique-emcasa/noticia/ivete-sangalo-faz-live-em-casa-de-pijama-sejam-bem-vindos.ghtml . Acesso em 18/09/2020

13 A regulamentação da publicidade das bebidas alcoólicas e a proteção do adolescente no Instagram e Facebook. Migalhas de Responsabilidade Civil. 2020. Disponível em:
}

https://www.migalhas.com.br/coluna/migalhas-de-responsabilidade-civil/327626/a-regulamentacao-da-publicidade-dasbebidas-alcoolicas-e-a-protecao-do-adolescente-no-instagram-e-facebookAcesso em 18/09/2020 
Becker usará como exemplo as Igrejas que ainda praticam o mecenato, que encomendam obras a artistas para decorar suas sedes e apresentar ao público com finalidade de melhorar a sua imagem e consequentemente atrair mais fiéis (BECKER, 2010, p.104). Nossa comparação entre ambos sistemas de patrocínio, tem como ponto de congruência a expansão de determinado tipo de consumo através da obra artística ou forma de circulação de um produto cultural, sem que haja a troca direta de mercadoria por dinheiro. Os artistas nas lives e as obras nas Igrejas, voltam a atenção do público, penetram no imaginário e o retorno financeiro se dá em outra esfera a posteriori.

Por fim, encerramos este artigo propondo uma análise acerca das lives, da sua estruturação e patrocínio, bem como para o público e as transformações na forma de se assistir espetáculos musicais. Se anteriormente enumeramos as principais mudanças advindas da música gravada, neste breve ensaio pontuamos algumas conjunturas das lives, as diferenciações materiais como também as simbólicas ligadas a individualização do lazer antes partilhado. Por estarmos vivendo uma circunstância nova e provavelmente momentânea, admitimos a dificuldade de estabelecermos conclusões bem delineadas. Nossa busca foi por traçar as principais diferenciações entre as lives independentes, as com fomentos governamentais e por fim as inseridas na indústria cultural de massa. Pautamos nossa análise nos investimentos financeiros de ambas e como isso repercute não apenas no número de audiência como nas liberdades de escolha dos artistas. Propomos uma associação entre os sistemas de mecenato e os sistemas de patrocínio de lives, uma vez que ambos consistem na criação de um imaginário e na vinculação do trabalho artístico a um financiador determinado. Afinal o lucro do investidor não está ligado à venda imediata e direta de mercadoria cultural ou artística, mas sim a um status social que o irá diferenciar dos demais. Se no modelo tradicional de mecenato a liberdade criativa do artista era questionada, nos parece fundamental questionarmos o mesmo dentro do nosso recorte. O espetáculo é uma mistura de interesses do artista, do produtor e nesse caso especificamente do patrocinador investidor. Logo o show que é apresentado deve atender mais do que o que o artista deseja mostrar, mas sim o que a indústria espera de retorno. Nas lives esse retorno vem na forma de audiência, e a audiência vem através de uma escolha de músicas conhecidas do público, na exibição da vida privada do artista, nas performances exuberantes. Até que ponto esse também é o desejo do artista? Na noção de sociedade espetacular de Debord, que reverencia o divertimento, a fronteira entre $\operatorname{arte}^{14}$ e indústria foi apagada, e esse duo se baseia na exploração das emoções e na valorização crescente do entretenimento. A cultura de massa é regida pelos interesses financeiros de quem detém o controle dos meios de comunicação, ou daqueles de patrocinam e apoiam eventos culturais. Por fim, concluímos que dentro das plataformas online se perpetua essa noção mítica e passadista da ascensão independente, autônoma, ou apologia mítica da ação individual do artista, de que a internet é um espaço democrático de divulgação de trabalhos. Porém, sustentamos que muito dificilmente os artistas independentes consigam atingir um grande público através das suas lives caseiras e assim, o monopólio da indústria cultural de massa segue incólume, seja nos espaços de circulação cultural tradicionais ou na pandemia de Covid-19.

\section{Referências Bibliográficas}

BECKER, Howard S. Mundos da arte. Lisboa: Livros Horizonte, 2010.

BENJAMIN, Walter. Obras Escolhidas: Magia e Técnica, Arte e Política. 3 Ed. São Paulo: Brasiliense, 1987.

CARVALHO, José Jorge. 'Espetacularização'e 'canibalização' das culturas populares na América Latina. Revista ANTHROPOLÓGICAS, ano 14, vol.21 (1): 39-76 , 2010

\footnotetext{
${ }^{14}$ Estamos falando aqui de artistas que estão de fato inseridos na economia da sociedade.
} 
DEBORD, Guy. A sociedade do Espetáculo. Rio de Janeiro: Contraponto, 1997.

LIPOVETSKY, Gilles. SERROY, Jean. A Estetização do Mundo: Viver na Era do Capitalismo Artista. São Paulo: Companhia das Letras, 2014.

\section{Outras Referências:}

A regulamentação da publicidade das bebidas alcoólicas e a proteção do adolescente no Instagram e Facebook. Migalhas de Responsabilidade Civil. 2020. Disponível em:

https://www.migalhas.com.br/coluna/migalhas-de-responsabilidade-civil/327626/a-regulamentacaoda-publicidade-das-bebidas-alcoolicas-e-a-protecao-do-adolescente-no-instagram-efacebookAcesso em 18/09/2020

Como as lives se tornaram centrais para os artistas da música. Nexo Jornal. Disponível em: https://www.nexojornal.com.br/expresso/2020/04/09/Como-as-lives-se-tornaram-centrais-para-osartistas-da-m\%C3\%BAsica: Acesso em: 10/09/2020

Estudo da ONU revela que mundo tem abismo digital de gênero. ONU News. 2019. Disponível em: https://news.un.org/pt/story/2019/11/1693711. Acesso em 25/08/2020

Forró Pé de Sesc. YouTube .2020. Disponpivel em: https://www.youtube.com/watch?v=IjkNA75CPUM\&t=6s. Acesso em 11/09/2020

Forró Dendi Casa. YouTube. 2020. Disponível em: https://www.youtube.com/watch?v=zJrus7_vFPw .Acesso em 11/09/2020

Ivete faz live em casa de pijama. GSHOW. 2020. Disponível em: https://gshow.globo.com/Famosos/fique-em-casa/noticia/ivete-sangalo-faz-live-em-casa-de-pijamasejam-bem-vindos.ghtml . Acesso em 18/09/2020

Lei Aldir Blanc de apoio a cultura é regulamentada pelo Governo Federal. Governo do Brasil. 2020. Disponível em:https://www.gov.br/pt-br/noticias/cultura-artes-historia-e-esportes/2020/08/lei-aldirblanc-de-apoio-a-cultura-e-regulamentada-pelo-governo-federal .Acesso em 18/09/2020

Marília Mendonça e Jorge e Mateus têm as lives mais assistidas do mundo na quarentena. Folha de S.Paulo.2020. Disponível em:

https://f5.folha.uol.com.br/musica/2020/05/marilia-mendonca-e-jorge-mateus-tem-as-lives-maisassistidas-do-mundo.shtml Acesso em 11/09/202

Restrições na transmissão ao vivo. Google Support. 2020. Disponível em:

https://support.google.com/youtube/answer/2853834?hl=pt-BR. Acesso em 18/09/2020

Show comandado por Elton John arrecada 8 milhões para caridade. G1. 2020. Disponível em: https://g1.globo.com/pop-arte/musica/noticia/2020/03/31/show-comandado-por-elton-john-de-casaarrecada-us8-milhoes-para-caridade.ghtml. Acesso em: 10/09/2020 